\title{
Failure of T-cell homeostasis preceding AIDS in HIV-1 infection
}

\author{
Joseph B. Margolick ${ }^{1}$, Alvaro MuÑoz ${ }^{2}$, Albert D. Donnenberg ${ }^{3}$, LaWrence P. Park ${ }^{2}$, \\ NOYA GALAI ${ }^{4}$, JaNis V. GIORGI ${ }^{5}$, MAURICE R.G. O'GORMAN ${ }^{6}$, JOHN FERBAS ${ }^{5}$, \\ FOR THE MULTICENTER AIDS COHORT STUDY*
}

\author{
${ }^{1}$ Department of Molecular Biology and Immunology, Johns Hopkins University School of Hygiene and Public Health, \\ Room 7032, 615 North Wolfe Street, Baltimore, Maryland 21205-2179, USA \\ ${ }^{2}$ Department of Epidemiology, Johns Hopkins University School of Hygiene and Public Health, \\ Room 795, 624 North Broadway, Baltimore, Maryland 21205, USA \\ ${ }^{3}$ Montefiore University Hospital, 3459 Fifth Avenue, Pittsburgh, Pennsylvania 15213, USA \\ ${ }^{4}$ The Hebrew Universtiy, Department of Ecological Medicine, Hadassah Medical School Jerusalem, P.O.B. 12272, \\ Code 91120 . Jerusalem, Israel \\ ${ }^{5}$ Department of Medicine, UCLA School of Medicine,12-939 FActor Building, 10833 Le Conte Avenue, \\ Los Angeles, California 90024-1745, USA \\ ${ }^{6}$ Department of Pediatrics, Northwestern University, 2300 Children's Plaza, Chicago, Illinois 60614, USA \\ Correspondence should be addressed to J.B.M.
}

\begin{abstract}
We and others have postulated that a constant number of $\mathrm{T}$ lymphocytes is normally maintained without regard to $\mathrm{CD4}^{+}$or $\mathrm{CD8}^{+}$phenotype ('blind' T-cell homeostasis). Here we confirm essentially constant T-cell levels (despite marked decline in $\mathrm{CD}^{+} \mathrm{T}$ cells and increase in $\mathrm{CD8}^{+} \mathrm{T}$ cells) in homosexual men with incident human immunodeficiency virus, type 1 (HIV-1), infection who remained free of acquired immunodeficiency syndrome (AIDS) for up to eight years after seroconversion. In contrast, seroconverters who developed AIDS exhibited rapidly declining T cells (both $\mathrm{CD4}^{+}$and $\mathrm{CD8}^{+}$) for approximately two years before AIDS, independent of the time between seroconversion and AIDS, suggesting that homeostasis failure is an important landmark in HIV disease progression. Given the high rate of T-cell turnover in HIV-1 infection, blind T-cell homeostasis may contribute to HIV pathogenesis through a CD8 ${ }^{+} \mathrm{T}$ lymphocytosis that interferes with regeneration of lost $\mathrm{CD4}^{+} \mathrm{T}$ cells.
\end{abstract}

Consistent features of HIV-1 infection are progressive loss of $\mathrm{CD}^{+} \mathrm{T}$ lymphocytes and increase in $\mathrm{CD}^{+} \mathrm{T}$ lymphocytes. In a three-year follow-up of incident cases of HIV infection in the Multicenter AIDS Cohort Study (MACS), we observed that these two processes tended to balance each other, beginning 1.5 years after seroconversion ${ }^{1}$. This led us to postulate a homeostatic mechanism that maintains a constant level of circulating $\mathrm{T}$ cells without regard to the phenotype $\left(\mathrm{CD} 4^{+}\right.$or $\left.\mathrm{CD} 8^{+}\right)$of the T cells ${ }^{1}$. The same mechanism was independently proposed by Adleman

\footnotetext{
"The Multicenter AIDS Cohort Study (MACS) includes the following: Baltimore: The Johns Hopkins University School of Hygiene and Public Health: Alfred J. Saah, Principal Investigator; Haroutune Armenian, Homayoon Farzadegan, Neil Graham Nancy Kass, Joseph Margolick, Justin McArthur, Ellen Taylor. Chicago: Howard Brown Memorial Clinic-Northwestern University Medical School: John P. Phair Principal Investigator; Joan S. Chmiel, Bruce Cohen, Maurice O'Gorman, Daina Variakojis, Jerry Wesch, Steven M. Wolinsky. Los Angeles: University of California, UCLA Schools of Public Health and Medicine: Roger Detels, Principal Investigator; Barbara R. Visscher, Irvin S.Y. Chen, Janice Dudley, John L. Fahey, John Ferbas, Janis V. Giorgi, Moon Lee, Oto Martínez-Maza, Eric N. Miller, Parunag Nishanian, Jeremy Taylor, Jerome Zack. Pittsburgh: University of Pittsburgh Graduate School of Public Health: Charles R. Rinaldo, Principal Investigator; Lawrence Kingsley, James T. Becker, Albert D. Donnenberg, Phalguni Gupta, Monto Ho, Sharon Zucconi. Data Coordinating Center: The Johns Hopkins School of Hygiene and Public Health:

Alvaro Munoz, Principal Investigator; Leonardo Epstein, Noya Galai, Stephen Gange, Donald R. Hoover, Lisa P. Jacobson, Lawrence P. Park, Kenrad Nelson, Steven Piantadosi, Sol Su. National Institutes of Health: National Institute of Allergy and Infectious Diseases: Lewis Schrager, Project Officer; National Cancer Institute: Daniela Seminara.
}

and Wofsy ${ }^{2}$, who reviewed evidence that it operates in HIV-negative populations such as bone marrow transplant recipients and experimental animals and termed the mechanism 'blind homeostasis' (ref. 3).

Recently, high rates of $\mathrm{CD}^{+} \mathrm{T}$-cell turnover in HIV-1 infection have been demonstrated ${ }^{4,5}$, highlighting the dynamic nature of the immune response to HIV infection and the need to understand how this response is regulated. Blind T-cell homeostasis, if it exists, could have important implications for the pathogenesis of HIV-1 infection. First, it would explain the stimulus to replace lost $\mathrm{CD}^{+}$cells. Second, it would account for the gradual shift in the balance between $\mathrm{CD}^{+}$and $\mathrm{CD} 8^{+} \mathrm{T}$ cells, since only the former would be lost from HIV-related mechanisms. Third, it predicts that the net preferential replacement of $\mathrm{CD}^{+} \mathrm{T}$ cells by $\mathrm{CD}^{+} \mathrm{T}$ cells would eventuate in critically low levels of $\mathrm{CD}^{+}$lymphocytes leading to immune failure. Importantly, only a very small net loss of $\mathrm{CD}^{+} \mathrm{T}$ cells per unit time would be sufficient to drive this process to a very low level of $\mathrm{CD}^{+} \mathrm{T}$ cells over the long incubation period of AIDS $^{2}$.

The follow-up described in our earlier report ${ }^{1}$ extended only to three years after seroconversion, a length of time when no more than $5 \%$ of subjects developed AIDS. In the present study, the follow-up extends to 8 years after seroconversion with substantially higher rates of AIDS cases. Patients with AIDS are well 
Fig. 1 Geometric means of absolute numbers of circulating T-cell subsets $\left(\mathrm{CD}^{+}, \mathrm{CD}^{+}\right.$, and $\mathrm{CD}^{+}$ lymphocytes) as a function of months since seroconversion in MACS seroconverters for whom the time of seroconversion was known to within \pm 4.5 months $(n=$ 372). Error bars indicate $95 \%$ confidence intervals, the estimated time of seroconversion. Numbers of observations at each data point, beginning at $<24$ months before seroconversion (the leftmost points on the graph), are 776,162 , $209,256,372,368,335$, $301,286,265,248,227$, 203, 195, 162, 155, 138, $121,107,90,65,86$. and the vertical dotted line

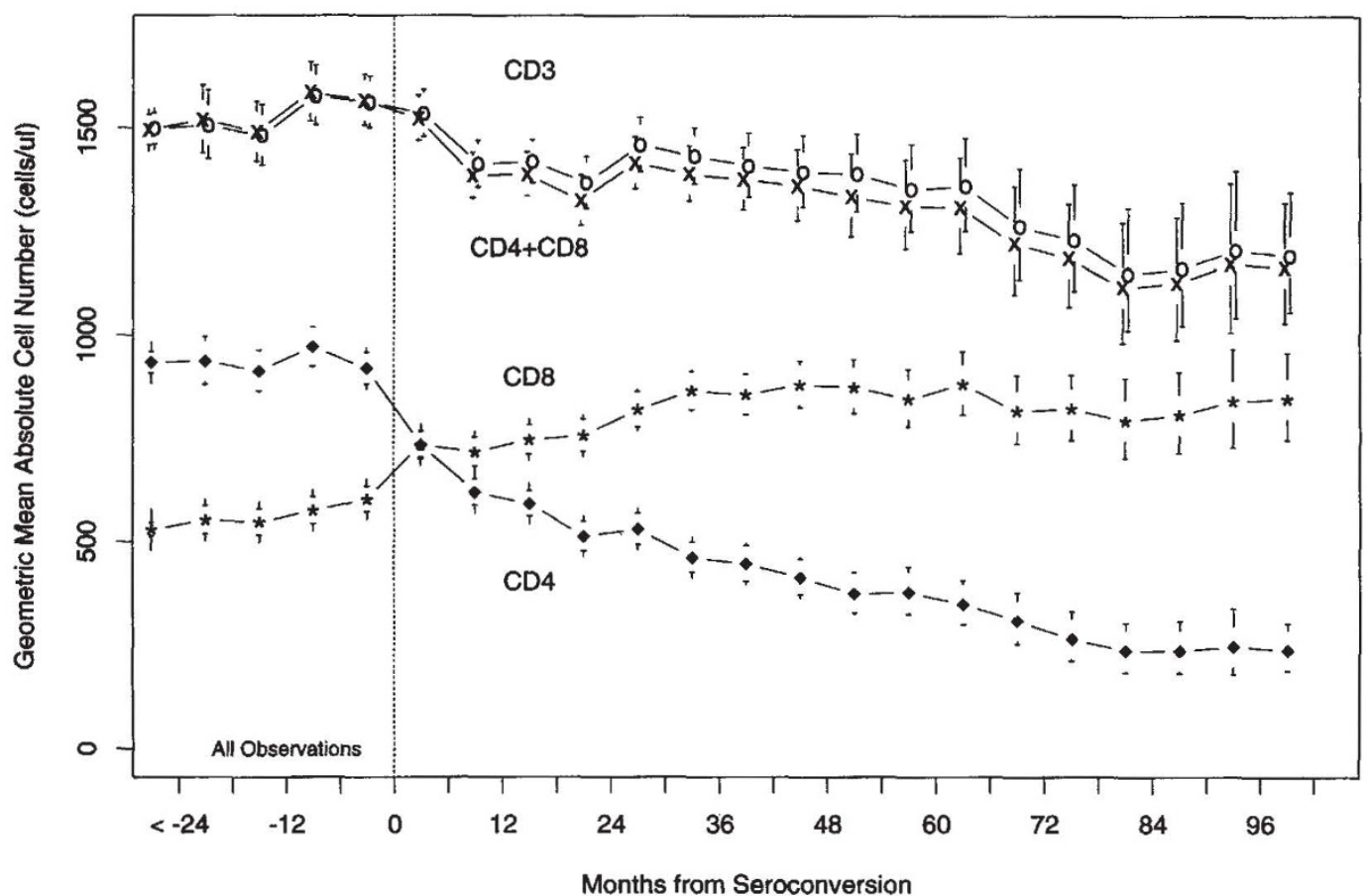

known to have depressed levels of total $T$ cells. Therefore, we could test not only whether blind T-cell homeostasis held true but how long before AIDS it fails. The longitudinal data provided by cohorts with precise dates of seroconversion and onset of AIDS allow forward (from seroconversion) and backward (from AIDS) analysis to present a comprehensive description of total T cells as well as the principal T-cell subsets $\left(\mathrm{CD}^{+}\right.$and $\left.\mathrm{CD} 8^{+}\right)$during the time between seroconversion and the onset of clinically defined AIDS. The results show that blind T-cell homeostasis is maintained for long periods after HIV-1 infection is established, but is lost in the last two years preceding AIDS.

\section{Preservation of blind T-cell homeostasis}

Circulating T-lymphocyte levels in the full sample of 372 MACS seroconverters with well-defined times of seroconversion are shown in Fig. 1. The sum of $\mathrm{CD}^{+}$and $\mathrm{CD} 8^{+}$lymphocytes essentially equalled the number of $\mathrm{T}$ cells and is not shown in subsequent figures. As previously reported, there was a progressive decline in $\mathrm{CD}^{+}$lymphocytes after seroconversion, more rapid for the first 6 to 12 months and then more gradual. $C D 8^{+}$lymphocytes rose similarly beginning at seroconversion. Total $\mathrm{T}$ (including $\mathrm{CD}^{+}$) lymphocytes declined slightly for the first 12 months after seroconversion and exhibited a gradual decline thereafter. Because T-cell levels are lower in AIDS than in earlier stages of HIV infection ${ }^{6}$, we hypothesized that this gradual decline of T lymphocytes was specifically due to lower T-cell levels in subjects who developed AIDS. As shown in Fig. 2, removal of observations from the 107 individuals who developed AIDS during the study period essentially abolished the decline in T-cell levels shown in Fig. 1, although a slight decline after 63 months persisted. A progressive decline in $\mathrm{CD}^{+}$lymphocytes (to a geometric mean of 380 cells per microlitre by 96 months after seroconversion) as well as a rise in $\mathrm{CD}^{+}$lymphocytes is shown in Fig. 2. This pattern again suggests a compensatory rise in $\mathrm{CD}^{+}$ lymphocytes in response to decline in $\mathrm{CD} 4^{+}$lymphocytes. It should be pointed out that the changes in $\mathrm{CD}^{+}$and $\mathrm{CD}^{+}$lym- phocytes were not precisely matched to the change in $\mathrm{CD}^{+}$lymphocytes at all time points; for example, between 45 and 81 months the $\mathrm{CD}^{+}$cell count changed only slightly while the $\mathrm{CD}^{+}$cell count declined at a variable rate. These discrepancies, as well as the decline in T cells after 63 months, could be due to imprecision in the compensatory mechanism, or to the fact that many AIDS-free seroconverters had limited follow-up (see legend to Fig. 2) and, therefore, could have been close to developing AIDS, as discussed below. Taken together, these data extend our previous observations on blind T-cell homeostasis for an additional 5 years after seroconversion, and thus provide compelling support for the postulated blind T-cell homeostatic mechanism.

\section{Loss of blind T-cell homeostasis 1.5-2 years before AIDS}

Given that in AIDS-free $\mathrm{HIV}^{+}$individuals the T-cell levels were relatively constant and that they are low at the onset of AIDS, we next investigated the trajectories of T-cell levels among the 92 seroconverters who had well-defined dates of onset of AIDS (Fig. $3)$. Very little change in T-cell levels was seen until approximately 1.5 years before AIDS. After this time, however, numbers of circulating $\mathrm{T}$ cells declined sharply. By regression analysis, the mean rate of change during the last 1.5 years before AIDS was $-14.2 \%$ per 6 months $(95 \%$ confidence interval $=-17.7 \%$ to $-10.6 \%)$, that is, the mean value for a given 6 -month period was equal to approximately $86 \%$ of the mean value for the preceding 6-month period. Over the 1.5-year period of decline, this corresponded to a decline from about 1,400 to about $900 \mathrm{~T}$ cells per microlitre at the onset of AIDS. In contrast, the estimate for the interval -1.5 to -3.5 years before AIDS was $-2.5 \%$, which was not significantly different from 0 (95\% confidence interval $=-5.1 \%$ to $+0.1 \%$ ). These results indicate a change in $\mathrm{T}$-cell homeostasis approximately 1.5 years before the onset of AIDS.

To determine whether these observations could have been affected by the use of antiretroviral therapy or Pneumocystis carinii pneumonia (PCP) prophylaxis, we performed a similar independent analysis on the seroprevalent (seropositive at study entry) 
Fig. 2 Similar to Fig. 1, except that observations from subjects who developed AIDS $(n=107)$ have been excluded from the analysis. Numbers of observations for each time point are as follows, beginning at the leftmost: 698, 136, 169, $195,265,262,236,212$, $195,182,164,157,139$, $136,114,114,100,89,81$, $70,51,71$.

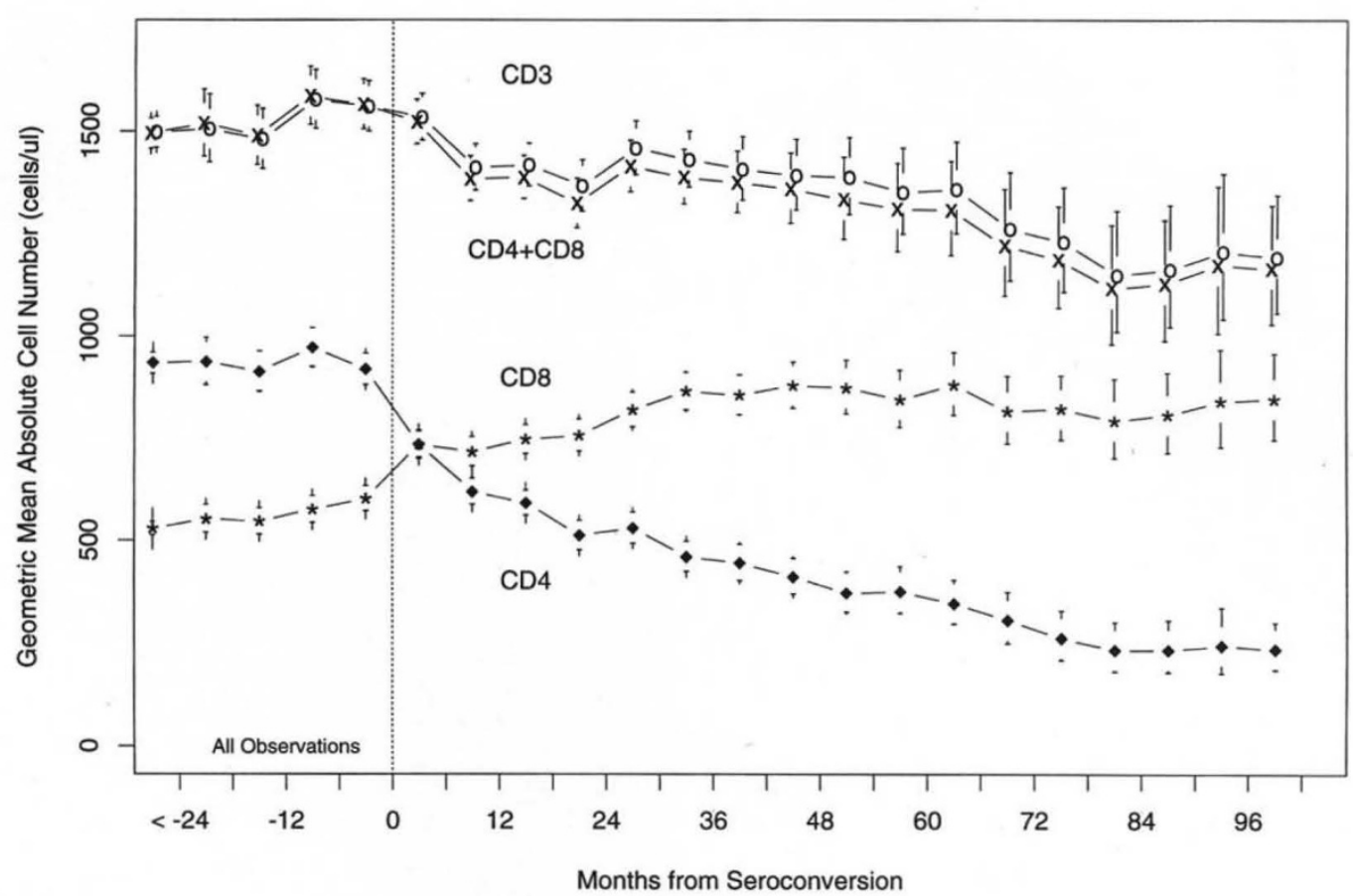

MACS participants who did not receive any retroviral therapy or PCP prophylaxis before developing AIDS $(n=624)$. In these men, the estimated rate of T-cell change was $-10.9 \%$ per 6 months for $0-1.5$ years before AIDS $(95 \% \mathrm{CI}=-12.5 \%,-9.4 \%)$. This estimate falls inside the $95 \%$ confidence interval calculated above for the corresponding interval for the seroconverters who developed AIDS. Also similar to the seroconverters, the estimated rate of change for the seroprevalent cases for the interval 1.5 to 3.5 years before AIDS was very small, $-0.4 \%$ per 6 months $(95 \% \mathrm{CI}=-1.7 \%$, $+0.9 \%$ ). Thus, our estimates of the timing and magnitude of T-cell changes before AIDS were independently confirmed in a second, untreated cohort, indicating that they were not substantially influenced by use of antiretroviral therapy or PCP prophylaxis.

\section{Downward inflection of T cells but not other cells}

The change in slope of $\mathrm{CD}^{+}$lymphocytes at 1.5 years before AIDS onset did not occur for other haematologic variables (Fig. 3). The only exception was the total lymphocyte count, which paralleled the T-cell count. This is not surprising since most lymphocytes are $T$ cells and the slope of non-T cells over time changed very little. Granulocytes and platelets declined at essentially constant rates over the 60 months preceding AIDS, and although the decline of hemoglobin has been reported to accelerate slightly around two years before AIDS ${ }^{7}$, this was not apparent here. In summary, the change in slope was larger and much more abrupt for $T$ cells than for any other cell type, implying a specific failure of homeostasis of $T$ cells preceding the onset of AIDS. This change in T-cell slope was reflected to a much smaller extent in changes in the percent of circulating $\mathrm{T}$ cells among lymphocytes, as measured in the standard flow cytometry assay gated on the total lymphocyte population. Specifically, mean T-cell percentages were $77.8,77.0,76.2$, and 73.5 percent at $21,15,9$, and 3 months before AIDS, respectively. This disparity is due to the parallel change in $\mathrm{T}$ and total lymphocytes shown in Fig. 3 and mentioned above.

\section{Consistency of time from failure of T-cell homeostasis to onset of AIDS}

We asked whether the relationship between failure of T-cell homeostasis and the onset of AIDS was dependent on the duration of HIV-1 infection. To address this question, the 92 seroconverters who developed AIDS at known times were stratified into four groups according to the time from seroconversion to AIDS $(0-3,3-4.5,4.5-6.0$, and $>6.0$ yrs $)$. The trajectories of the total $\mathrm{CD}^{+}, \mathrm{CD}^{+}$, and $\mathrm{CD}^{+} \mathrm{T}$ cells for these four groups are depicted in Fig. 4. Two conclusions can be drawn from these data. First, for the groups that had sufficiently long pre-AIDS intervals (groups 2-4), levels of $\mathrm{CD}^{+}$lymphocytes were essentially constant during most of the time from seroconversion until approximately 18 months before the onset of AIDS. Second, the slopes at which T cells declined in the 18 months preceding AIDS were remarkably similar for the four groups. Regression analysis of these data (Table 1) confirmed that the four T-cell slopes in the 1.5 years before AIDS were statistically different from zero, but not from each other $(P=$ 0.15 ), and that earlier slopes for all groups were close to zero. The entries in Table 1 correspond to -[1 - exp (slope)], where slope is the 6-month rate of change of the log-transformed $\mathrm{CD}^{+}$lymphocyte counts for a given period before the onset of AIDS. In the piecewise linear model used (described in detail in ref. 8), the slopes correspond to sums of regression coefficients whose standard errors are obtained using the covariance matrix from maximum likelihood procedures.

$\mathrm{CD}^{+}$and $\mathrm{CD}^{+} \mathrm{T}$ cells showed very different patterns around the time that total $\mathrm{T}$ cells began to decline, with $\mathrm{CD}^{+}$lymphocytes accelerating their decline slightly and $\mathrm{CD}^{+} \mathrm{T}$ cells leveling off, then beginning to decline (Fig. 4). Overall, loss of $\mathrm{CD}^{+} \mathrm{T}$ cells contributed slightly more than loss of $\mathrm{CD} 4^{+} \mathrm{T}$ cells to the decline in total $\mathrm{T}$ cells in the 1.5 years preceding AIDS. The mean levels of circulating $\mathrm{CD}^{+}$lymphocytes present 21 months before AIDS in the four seroconverter groups were 622, 322, 328 and 283 per microlitre, respectively. The corresponding figures for 15 
Fig. 3 Geometric means of haematologic measurements as a function of months before (negative numbers) or after (positive numbers) the onset of AIDS ( $t=0$, vertical dotted line). G, granulocytes; $P$, platelets; L, lymphocytes; $\mathrm{H}$, hemoglobin; $\mathrm{T}, \mathrm{CD}^{+}(\mathrm{T})$ lymphocytes; and N, non-T lymphocytes (defined as $\mathrm{CD}^{-}$lymphocytes). Cell counts $(G, L, T, M, N)$ are in cells per microlitre, haemoglobin in grams $\times 10^{-2}$ per $100 \mathrm{ml}$, and platelets in cells $\times 10^{2}$ per microlitre. Numbers of observations at each data point, beginning with the leftmost and ending at the first point after onset of AIDS, are: $29,18,28,32,41$, $47,56,59,68,73,71,73$, $76,65,53,40$.

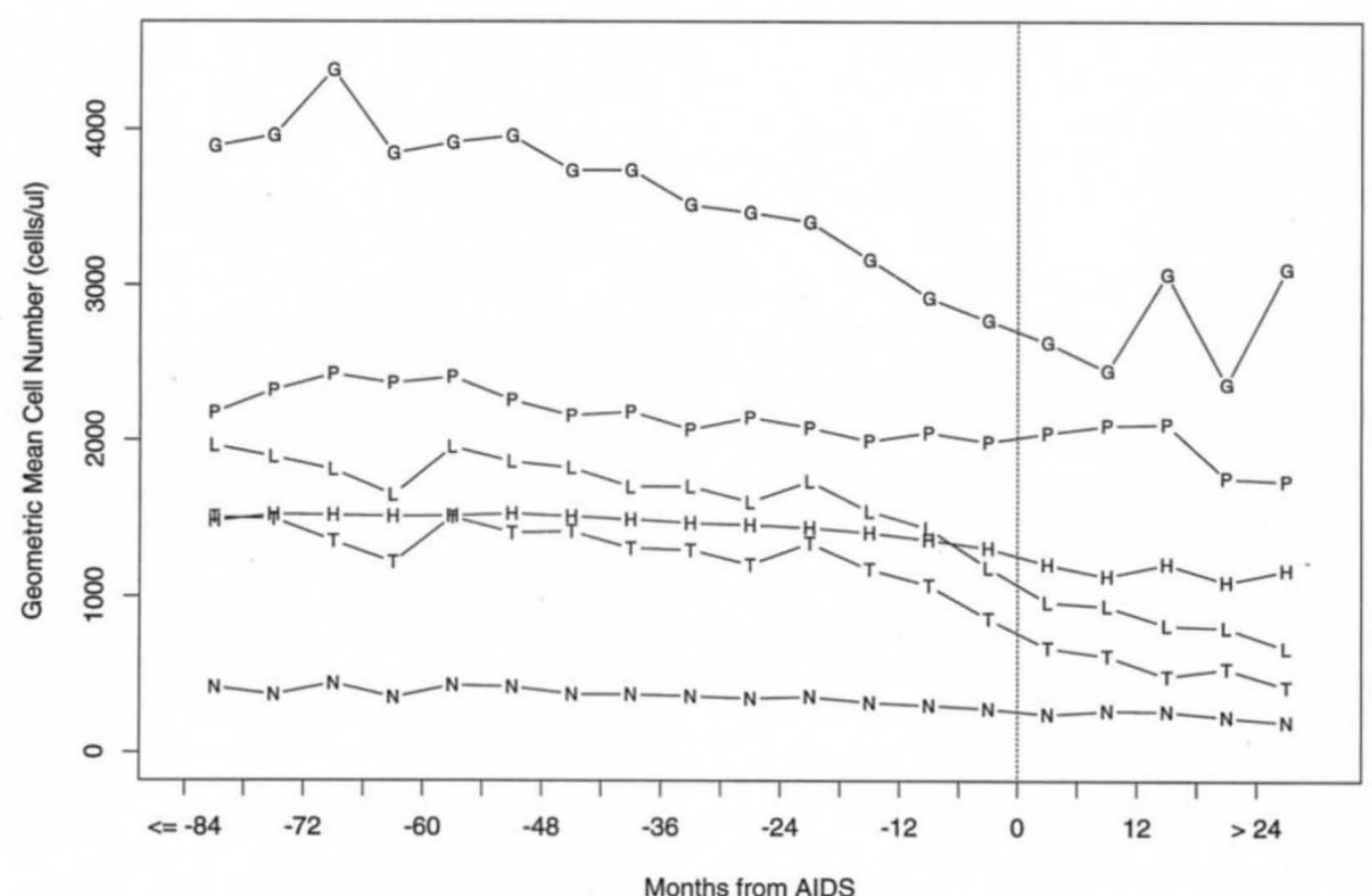

months before AIDS onset were $399,287,234$, and 186 per microlitre, respectively.

\section{Discussion}

Regulated T-cell turnover during the incubation period of AIDS HIV-1 causes a chronic disease that can take many years to run its course. Our understanding of HIV progression is changing from the paradigm of a slow virus infection to that of a raging war between the virus and the immune system. Recently, unexpectedly high rates of $\mathrm{CD}^{+} \mathrm{T}$-cell turnover in HIV-1 infection were demonstrated ${ }^{4,5}$. Here, we complement these studies by addressing the homeostatic regulation of this turnover, the balance of $\mathrm{T}$-cell populations that is maintained, and the consequences of homeostatic failure. We show that numbers of circulating T lymphocytes remained constant, or nearly so, in HIV-1 seroconverters who were AIDS-free during the follow-up period, despite profound shifts in $\mathrm{CD}^{+}$and $\mathrm{CD}^{+} \mathrm{T}$-cell subsets. Among the subjects who did develop AIDS, the T lymphocytes were constant, or nearly so, up to 2 years before AIDS onset, when they declined. Further, failure of the blind homeostatic mechanism in the period before AIDS largely, if not completely, explained the declining T-cell levels in the cohort as a whole. According to these results, the gradual decline in $\mathrm{CD}^{+}$lymphocytes that is well recognized as a cardinal feature of HIV infection could be a regulatory phenomenon due to slow net loss of $\mathrm{CD} 4^{+}$lymphocytes. Underlying this gradual net change is a far more dynamic process in which substantial T-cell losses are continually offset by a homeostatic replacement mechanism ${ }^{1,2,9,10}$.

Failure of T-cell homeostasis may represent a precipitating event in the progression to AIDS, as suggested by three findings of this study. First, the timing and magnitude of the T-cell decline relative to the onset of AIDS were remarkably consistent regardless of the interval between seroconversion and AIDS onset. Second, the downward inflection point in T-cell levels at approximately 18 months before AIDS was unique to $\mathrm{CD}^{+}$ $\mathrm{T}$ cells. Third, the loss of $\mathrm{T}$ cells was due to substantial declines in both $\mathrm{CD}^{+}$and $\mathrm{CD}^{+} \mathrm{T}$ cells, indicating a relative failure of production of both $\mathrm{T}$-cell subsets. $\mathrm{CD4}^{+} \mathrm{T}$ cells play a central role in initiating immune responses ${ }^{11}$, and $\mathrm{CD}^{+}$lymphocytes mediate several types of host defence against HIV, including cytotoxicity
Table 1 Rates of T-cell decline in HIV-1 seroconverters by time periods before AIDS

Years before AIDS

Percent change in $\mathrm{CD}^{+}$levels by seroconverter group (years from seroconversion to AIDS)

$$
\begin{array}{ccccc} 
& <3.0 \mathrm{yr} & 3.0-4.5 \mathrm{yr} & 3.5-6.0 \mathrm{yr} & >6.0 \mathrm{yr} \\
-1.5 \text { to } 0 & -14.9 & -11.6 & -14.0 & -13.2 \\
& (-22.5,-6.5) & (-17.5,-5.3) & (20.4,-7.0) & (-19.4,-6.4) \\
-3.5 \text { to }-1.5 & 0.4 & 1.8 & -1.6 & -5.5 \\
& (-14.0,17.1) & (-5.5,2.0) & (-6.2,3.2) & (-9.8,-1.0) \\
<-3.5 & & & -1.2 & 0.0 \\
& & & (-7.0,5.0) & (-2.6,2.6)
\end{array}
$$

*Data are means (95\% confidence interval) of the percent change in $\mathrm{CD}^{+}$lymphocyte count per 6 months in the time period indicated.

Slopes of T-cell decline per 6 months, expressed as a percentage of the value at the beginning of each 6-month period, determined as described in the Methods. Confidence intervals including 0 indicate a mean that is not statistically different from 0 at the level of $P=0.05$.

Slopes for the four groups at 0-1.5 years before AIDS are not statistically different from each other. Changes in $\mathrm{CD}^{+}$lymphocytes in the intervals more than 1.5 years before AIDS were not significantly different from 0 , except for group 4 which exhibited a marginally significant decline in the interval 1.5-3.5 years before AIDS. 
against infected cells ${ }^{12-14}$ and suppression of replication $^{15,16}$. Thus, the decline of both $\mathrm{CD}^{+}$and $\mathrm{CD}^{+} \mathrm{T}$ cells due to inadequate compensatory T-cell production could explain, at least in part, both the loss of immune function and the increase in HIV load that characterize the last 1.5 to 2 years before an AIDS-defining illness ${ }^{17}$.

What could account for this failure of homeostasis? One possibility is an increase in T-cell destruction. Although Ho et al. ${ }^{4}$ and Wei et al. ${ }^{5}$ demonstrated a high rate of $\mathrm{T}$-cell replacement, their studies were cross-sectional. Thus, it remains possible that $\mathrm{T}$. cell replacement in their donors, although high, was lower than it had been earlier in the disease process. Specifically, progression of HIV disease in the 1.5 to 2 years before AIDS could primarily reflect compensation failure, with no abrupt change in underlying HIV disease activity such as an increase in viral load or change in viral properties (these changes could fol-

low consequent to loss of adequate T-cell homeostasis). Although no one would dispute the need for direct antiviral therapy, it follows from the above interpretation that maintenance of compensatory T-cell production could also be an important target of therapy for HIV infection. These processes need not be mutually exclusive. For example, HIV may suppress T-cell replacement through direct or indirect mechanisms. Another possibility is that a certain level of $\mathrm{CD} 4^{+}$lymphocyte function is needed to support T-cell homeostasis, and this is lost as the CD4 ${ }^{+}$ level declines. In support of this possibility, apoptosis of both $\mathrm{CD}^{+}$and $\mathrm{CD}^{+} \mathrm{T}$ cells in short-term unstimulated cultures increases as $\mathrm{CD}^{+}$numbers decline in HIV infection ${ }^{18,19}$. Since apoptosis accompanies lymphopoiesis ${ }^{19}$, progressive failure of newly produced $\mathrm{CD}^{+}$and $\mathrm{CD}^{+}$lymphocytes to survive to maturity could account for this finding.

Although we have identified the time point of failure to the nearest 6-month interval for the groups studied, the precise timing of this event is less important than the fact that it occurs substantially before the onset of AIDS. It is not essential for the hypothesis that $\mathrm{T}$-cell decline before the inflection point before AIDS be exactly zero, or that decline in $\mathrm{CD}^{+}$lymphocytes precisely match increase in $\mathrm{CD8}^{+}$lymphocytes. In fact, T cells declined very slightly throughout our study ${ }^{9}$, and changes in $\mathrm{CD}^{*}$ and $\mathrm{CD} 8^{+}$lymphocytes were not always exactly reciprocal. These findings could be due to a lag in the ability of T-cell production to keep pace with a gradually accelerating loss of $\mathrm{CD}^{+} \mathrm{T}$ cells, or to variable follow-up of the cohort. The essential point is that homeostatic mechanisms result in nearly complete compensation for T-cell loss but undergo a marked deterioration at some time before AIDS.

The results presented here were obtained using parametric regression methods for the analysis of repeated measurements allowing the within-individual correlation of the $\mathrm{CD}^{+}$lymphocyte counts to have a damped exponential correlation structure ${ }^{8}$. Alternative models for the correlation structure are provided by random-effects models, which allow different individuals to have different slopes. The average of the individual slopes then provides the description of the rate of change at the population level. We fit these random-effects models, and the estimates were virtually identical to those in Table 1; despite higher standard errors under the random-effects models, the inferences (that is, significant results) were unchanged.

\section{Other implications of blind T-cell homeostasis in HIV pathogenesis}

Preservation of T-cell homeostasis could explain why some HIV ${ }^{+}$ individuals, who maintain high levels of $\mathrm{CD}^{+}$lymphocytes in the face of $\mathrm{CD}^{+}$counts of $<200$ per microlitre, remain AIDS-free 
for many years. More generally, relatively slight individual-toindividual variation in the ability to replace lost $\mathrm{T}$ lymphocytes could contribute to the variability of the incubation period of AIDS.

The loss of T-cell homeostasis also focuses attention on events occurring 11/2-2 years before the onset of AIDS. Rates of decline of other haematologic parameters, including $\mathrm{CD4}^{+}$lymphocytes and haemoglobin ${ }^{7,8,20}$, are altered beginning approximately two years before the diagnosis of AIDS, although these alterations are subtle compared to the pronounced inflection of $\mathrm{CD}^{+}$lymphocytes and were not seen in the present study. This is also the time frame in which syncytium-inducing HIV isolates can emerge $^{21}$. Loss of T-cell homeostasis could be secondary to any of these or other related events, such as deterioration of lymphoid tissues ${ }^{22,23}$ or possibly loss of the ability to generate CD8 $8^{+}$lymphocytes that can control HIV. To address these questions, it will be important to establish the timing of failure of T-cell homeostasis relative to these other events in individual subjects.

Clearly, failure of T-cell homeostasis is only one of many pathogenetic mechanisms in HIV infection, because substantial T-cell dysfunction and loss of $\mathrm{CD}^{+}$lymphocytes have usually occurred by the time $\mathrm{T}$ cell numbers begin to fall (though not always, as shown by Group 1 in Fig. 4). Moreover, as we have previously suggested, T-cell turnover may result in a gradual replacement of normal $\mathrm{T}$ cells with hypofunctional cells over the course of HIV infection ${ }^{1}$. Such a mechanism could contribute to the changes in activation level, phenotypic expression, and/or function of circulating $\mathrm{T}$ cells that are evident in all stages of HIV infection (reviewed in refs 24, 25), as well as to the eventual failure of $\mathrm{T}$-cell homeostasis as demonstrated in this study. The possibility that T-cell homeostasis in the peripheral blood is due to redistribution of tissue $T$ cells, rather than the production of new $T$ cells, must also be considered. Arguing against this possibility is the report that mice depleted of $\mathrm{CD4}^{+}$lymphocytes in both blood and tissues using anti-CD4 monoclonal antibody exhibited a compensatory increase in $\mathrm{CD}^{+}$lymphocytes in lymph nodes and spleen which paralleled those in the blood ${ }^{2}$.

Despite these uncertainties, failure of T-cell homeostasis appears to represent a recognizable and clinically significant landmark in the natural history of HIV infection. As such, measurements of all T-cell subsets, not just the $\mathrm{CD}^{+}$subset, may provide important information for the monitoring of patients and the design of drug and vaccine trials. The present study supports the exploration of treatment strategies for HIV infection which include maintaining and/or augmenting the physiologic replacement of lost $\mathrm{T}$ cells (both $\mathrm{CD}^{+}$and $\mathrm{CD} 8^{+}$).

\section{Methods}

Study population and definition of seroconverters. The study design was similar to that previously reported ${ }^{1}$ and is summarized here. Homosexual/bisexual men in the MACS were seen twice yearly for physical examination and laboratory testing. HIV-1 seropositivity was defined as a positive ELISA and a western blot with bands corresponding to at least two of the following genes of HIV-1: gag, pol, and env. Of the 5,579 men enrolled, 3,388 were seronegative at baseline and 466 of these (13.7\%) became seropositive (seroconverted) between 1984 and 1993 . The date of seroconversion was defined as halfway between the last seronegative and the first seropositive visit. The present analysis used data from the 372 seroconverters whose date of seroconversion was known to within \pm 4.5 months, and included data through 9/30/93. The 1987 CDC defini- tion of AIDS, which relies on symptoms rather than CD4 $4^{+}$lymphocyte counts to define AIDS ${ }^{26}$, was used, because we were interested in the relationship between T-cell levels and the clinical status of the study subjects. Under this definition, 107 seroconverters developed AIDS during the study period. This included 92 for whom the date of onset was known based on confirmed medical records, and was thus highly reliable, and 15 for whom AIDS was diagnosed postmortem and thus the date of onset was unknown.

Measurement of T-cell subset levels. Peripheral blood mononuclear cells were stained with monoclonal antibodies by a wholeblood lysing method ${ }^{27}$ and analysed by two-color flow cytometry by using procedures that have been described ${ }^{28,29}$ and monoclonal antibodies specific for CD3, CD4, and CD8 (Becton Dickinson Immunocytometry Systems, San José, California). Absolute numbers of cells per microlitre of blood were calculated using the complete blood count with automated 10,000 cell differential.

Statistical methods. To investigate longitudinal changes in haematologic parameters, data were grouped into 6-month intervals based on time relative to seroconversion or the diagnosis of AIDS. Data are given as geometric means and $95 \%$ confidence intervals of the means. Individuals who developed AIDS provide data to retrospectively describe the trajectories of $\mathrm{CD}^{+}$lymphocyte counts. These trajectories were analysed with a regression model applied to post-seroconversion data from the AIDS cases in the seroconverter and seroprevalent members of the MACS cohort. Before we fit the regression model, we tested whether the $\mathrm{CD}^{+}$lymphocyte counts fulfilled the normality assumption at each of the 22 semesters from seroconversion that we analysed. We found that all but two failed the normality test, whereas only 3 of the 22 semesters failed if the $\mathrm{CD}^{+}$lymphocyte counts were log-transformed. Therefore, we carried out the regression analysis in the log scale of the $\mathrm{CD}^{+}$lymphocyte counts, and we present the geometric mean as the corresponding descriptive statistic. In spite of the appropriateness of the log transformation, we also fit the final regression model using the raw $\mathrm{CD} 3$ cell counts and found the inferences to be robust with respect to the transformation.

The model provided estimates of average $\mathrm{CD}^{+}$lymphocyte count at the onset of AIDS as well as slopes (rates of change) of $\mathrm{CD}^{+}$lymphocytes in the intervals $0-1.5,1.5-3.5$, and $>3.5$ years before the onset of AIDS. These intervals were selected based on preliminary analyses exploring smaller intervals to identify the time points where the changes in slopes were greatest. Slopes for time periods containing small numbers of observations were not calculated. Correlations of repeated observations obtained from each individual were taken into account by using a two-parameter damped exponential correlation structure, which has been shown to model T-cell subsets appropriately ${ }^{8}$. To assess the consistency of the trajectories according to the times from seroconversion to AIDS, the 92 AIDS cases were divided into 4 groups $(\leq 3,3$ to $4.5,4.5$ to 6 , and $>6 \mathrm{yr}$ ), such that each group had similar numbers of individuals and observations (Fig. 4).

Note added in proof: The high rates of $\mathrm{CD}^{+}$lymphocyte turnover reported in refs 4 and 5 are controversial (Nature 375: 193-198, 1995). The high rates of apoptosis of both $\mathrm{CD} 4^{+}$and $\mathrm{CD} 8^{+} \mathrm{T}$ cells in short-term unstimulated cultures, as discussed above, are consistent with high T-cell turnover. However, the importance of blind T-cell homeostasis in the pathogenesis of profound $\mathrm{CD4}^{+}$ lymphocyte depletion does not depend on the magnitude of Tcell turnover, but rather on the preferential destruction of $\mathrm{CD}^{+}$ over CD8* $\mathrm{T}$ cells. 


\section{Acknowledgements}

We thank Elvia Scott, Patricia Hultin, LuAnn Borowski, Alison Logar, James Martin, Gertrude Meiers, and Samuel Wu for performance of flow cytometry, and the MACS participants for their dedication to this study. Grant support: grants AI 32535, AI 72634, AI 72631, AI 72676, AI 72632, AI 28748, AI 32376 , and AI 25326 from the National Institutes of Health. A.D.D. is the recipient of a Carter-Wallace fellowship in AIDS research.

\section{RECEIVED 7 FEBRUARY; ACCEPTED 23 MAY 1995}

1. Margolick, J.B. et al. Changes in T and non-T lymphocyte subsets following seroconversion to HIV-1: Stable CD3+ and declining CD3- populations suggest regulatory responses linked to loss of CD4 lymphocytes. J. AIDS 6, 153-161 (1993).

2. Adleman, L.M. \& Wofsy, D. T-cell homeostasis: Implications in HIV infection. I. AIDS 6, 144-152 (1993)

3. Adleman, L.M. \& Wofsy, D. Blind homeostasis in CD4 knockout mice. First nath. Conference on Human Retroviruses and Related Infections (12-16 December 1993 Washington, DC, Abstr. 280 (Am. Soc. Microbiol., Washington, DC, 1993).

4. Ho, D.D. et al. Rapid turnover of plasma virions and CD4 lymphocytes in HIV-1 infection. Nature 373, 123-126 (1995).

5. Wei, $\mathrm{X}$. et al. Viral dynamics in human immunodeficiency virus type 1 infection. Nature 373, 117-122 (1995).

6. Zolla-Pazner, S. et al. Nontandom development of immunologic abnormalities after infection with human immunodeficiency virus: Implications for im munologic classification of the disease. Proc. natn. Acad. Sci. U.S.A. 84, 5404-5408 (1987)

7. Hoover, D.R. et al. The progression of untreated HIV-1 infection prior to AIDS. Am. J. Public Hlth 82, 1538-1541 (1992)

8. Galai, N. et al. Tracking of markers and onset of disease among HIV-1 seroconverters. Statist. Med. 12, 2133-2145 (1993).

9. Margolick, J.B., Donnenberg, A. \& Muñoz, A. T lymphocyte homeostasis after HIV seroconversion. J. acquir. Immun. Defic. Syndr. 8, 415-416, 1994.

10. Ascher, M.S. \& Sheppard, H.W. AIDS as immune system activation. II. The panergic imnesia hypothesis. J. acquir. Immun. Defic. Syndr. 3, 177-91. (1990).

11. Meuer, S.C. et al. Cellular origin of interleukin 2 in man: Evidence for stimulus restricted IL2 production by $\mathrm{T}^{+}$and $\mathrm{T}^{+}$lymphocytes. I Immun. 129, 1076-1079 (1982).

12. Walker, B.D. et al. HIV-specific cytotoxic $T$ lymphocytes in seropositive individuals. Nature 328, 345-348 (1987).

13. Koenig, S. et al. Group-specific, major histocompatibility complex class I-re- stricted cytotoxic responses to human immunodeficiency virus 1 (HIV-1) envelope proteins by cloned peripheral blood T cells from an HIV-1-infected individual. Proc. natn. Acad. Sci. U.S.A. 85, 8638-8642 (1988)

14. Ho, H.-N. et al. Circulating HIV-specific CD8+ cytotoxic T cells express CD38 and HLA-DR antigens. J. Immun. 150, 3070-3079 (1993).

15. Mackewicz, C.E., Ortega, H.W. \& Levy, J.A. CD8+ cell anti-HIV activity correlates with the clinical state of the infected individual. J. clin. Invest. 87, 1462-1466 (1991).

16. Hausner, M.A., Giorgi, J.V. \& Plaeger-Marshall, S. A reproducible method to detect CD8 T cell mediated inhibition of HIV production from naturally infected CD4 cells. J. immunol. Methods 157, 181-187 (1993).

17. Pantaleo, G., Graziosi, C. \& Fauci, A. The immunopathogenesis of human immunodeficiency virus infection. New Engl. J. Med. 328, 327-335 (1993).

18. Gougeon, M.L. \& Montagnier, L. Apoptosis in AIDS. Science 260, 1269-1270 (1993).

19. Donnenberg, A.D., Margolick, J.B., Beltz, L.A., Donnenberg, V.S. \& Rinaldo, C.R. Apoptosis parallels lymphopoiesis in bone marrow transplantation and HIV disease. Res. Immun. 146, 11-21 (1995).

20. Lang, W. et al. Patterns of $T$ lymphocyte changes with human immunodeficiency virus infection: From seroconversion to the development of AIDS. J. ac quir. Immun. Defic. Syndr. 2, 63-69 (1989).

21. Koot, M. et al. Prognostic value of HIV-1 syncytium-inducing phenotype for rate of CD4+ cell depletion and progression to AIDS. Ann. intern. Med. 118, 681-688 (1993).

22. Pantaleo, G. et al. HIV infection is active and progressive in lymphoid tissue during the clinically latent stage of disease. Nature 362, 355-358 (1993).

23. Embretson, J. et al. Massive covert infection of helper T lymphocytes and macrophages by HIV during the incubation period of AIDS. Nature 362 359-362 (1993).

24. Giorgi, J.V. \& Janossy, G. Flow cytometry studies in HIV disease: Relevance to AIDS vaccine development. AIDS 8 (suppl. 1), S183-S193 (1994).

25. Donnenberg, A.D., Margolick, J.B. \& Donnenberg, V.S. Lymphopoiesis, apoptosis, and immune amnesia. Ann. N.Y. Acad. Sci. (in the press).

26. Centers for Disease Control. Revision of the CDC surveillance case definition for acquired immunodeficiency syndrome. Morbid. Mortal. Weekly Rep. 36, 3S-15S (1987).

27. Hoffman, R.A., Kung, P.C., Hansen, W.P. \& Goldstein, G. Simple and rapid measurement of human $T$ lymphocytes and their subclasses in peripheral blood. Proc. natn. Acad Sci 77, 4914-4917 (1980).

28. Giorgi, J.V. et al. Quality control in the flow cytometric measurement of T-lymphocyte subsets: the Multicenter Aids Cohort study (MACS) experience. Clin. Immun. Immunopathol. S5, 173-186 (1990).

29. Schenker, E.L. et al. Evaluation of a dual-color flow cytometry immunophenotyping panel in multicenter quality assurance program. Cytometry 14, 307-317 (1993). 